\title{
Discussion: How one shall interpret "spirit of mutual trust and co-operation" in NEC contracts
}

Bryan C. H. Kwok MSc, BEng

Hong Kong University of Science and Technology, Hong Kong

(Orcid:0000-0002-5526-317X) (corresponding author:

brian12111993@hotmail.com)
Raymond H. M. Leung BASC, MASC, PhD, FICE, FHKIE, FASCE, FIIE, FHKIArb, PEng, CEng, SmIEEE, RPE

Adjunct Professor, Department of Civil and Environmental Engineering, Hong Kong University of Science and Technology, Hong Kong; Adjunct Professor, Department of Real Estate and Construction, University of Hong Kong, Hong Kong (Orcid:0000-0003-1158-8375)

Joe Colgan

Senior Project Manager, Octa Associates Ltd, Christchurch, New Zealand

is a danger that reciprocal claims under the same banner could be spawned - that is, the act of seeking to prosecute a breach of the Somtac clause is itself, if considered meritless, a breach that may be claimed, and the initial assessment of that is simply subjective opinion.

It would also, the contributor thinks, be relatively easy to put some basic structure around what that obligation equates to in terms of behaviour at a general level.

Contracts do not cater for every possible circumstance. If they did, there would be no need for a civil judiciary, and seeking to prescribe a remedy for every conceivable combination of conditions is a task that can never be completed.

That does not detract, though, from the effort to promote a collaborative, working arrangement by virtue of a contractual clause that has at least some sanction if it is ignored.

\section{Authors' reply}

The authors agree with the observation that there is a limited amount of case law supplementing the interpretation of the clause. Yet based on this understanding, it seems that the parties will be bound by this clause without fully understanding its implication and impact, until the issue is brought to the tribunal or court. Putting forward a contractual issue to the tribunal or court is obviously not the drafting intention of the contract.

Unlike the rule of repudiation and misrepresentation, the clause is explicitly introduced in the contract. This means that the parties both agree to such a clause (consensus ad idem) or else there will be no contract. With the interpretation of the clause awaited, it seems that the contract is not founded concretely.

Resorting the issue to a compensation event is a possible mitigation measure, but once again it begs the question: why the hole cannot be plugged before it leaks? Resolving contractual issues through the compensation event mechanism will essentially increase uncertainty to contract. It is further notable that being a core clause and possibly foundation of the contract, time and cost implication arising from this clause cannot be easily assessed and 
agreed. Assessment among different users may deviate significantly depending on their personal understanding of the clause. This thus again becomes a ground for dispute.

The authors also agree that a contract cannot take into account all possible circumstances. However, it is also not desirable to include a clause that is not well explained and provide unnecessary flexibility for the parties to argue.

\section{REFERENCES}

Leung RHM and Kwok BCH (2020) How one shall interpret 'spirit of mutual trust and co-operation' in NEC contracts. Proceedings of the Institution of Civil Engineers - Management, Procurement and Law 173(1): 14-20, https://doi.org/10.1680/jmapl.18.00051.

\section{How can you contribute?}

To discuss this paper, please email up to 500 words to the editor at journals@ice.org.uk. Your contribution will be forwarded to the author(s) for a reply and, if considered appropriate by the editorial board, it will be published as discussion in a future issue of the journal.

Proceedings journals rely entirely on contributions from the civil engineering profession (and allied disciplines). Information about how to submit your paper online is available at www.icevirtuallibrary.com/page/authors, where you will also find detailed author guidelines. 